\title{
Attenuation of isocapnic hyperpnoea-induced guinea-pig bron- choconstriction by chronic hypoxia
}

\author{
Y-L. Lai, C.W. Lin, L-C. Lai
}

Attenuation of isocapnic hyperpnoea-induced guinea-pig bronchoconstriction by chronic hypoxia. Y-L. Lai, C.W. Lin, L-C. Lai. OERS Journals Ltd 1998.

ABSTRACT: Chronic hypoxia has been shown to augment the production of antioxidants in rat lungs and to reduce airway hyperreactivity in patients with asthma. This study investigated indirectly whether this increase in antioxidants occurs in guineapig lungs and whether the increased antioxidants affect hyperpnoea-induced bronchoconstriction (HIB).

Guinea-pigs were divided into four groups: $\operatorname{control}(n=8)$; chronic hypoxia $(n=7)$; capsaicin pretreatment $(n=7)$; and capsaicin pretreatment plus chronic hypoxia $(n=8)$. Control animals were not treated. Animals in the hypoxia group were intermittently exposed to an ambient pressure of $380 \mathrm{mmHg}$ for 7 days. A five day pretreatment of capsaicin was used to deplete tachykinins. In the last group, animals were pretreated with capsaicin, followed by a seven day hypoxic exposure. On the day of the study, airway function was examined in the anaesthetized and paralysed animal.

Fifteen minutes of hyperpnoea caused marked decreases in the maximal expiratory flow rate at $15 \%$ vital capacity, forced expiratory volume in one second, and dynamic respiratory compliance, indicating HIB. This HIB and plasma substance P levels were significantly attenuated by chronic hypoxia, capsaicin pretreatment, and capsaicin pretreatment plus chronic hypoxia. Furthermore, chronic hypoxia attenuated airway constriction induced by xanthine-xanthine oxidase.

The results suggest that chronic hypoxia attenuates hyperpnoea-induced bronchoconstriction via a decrease in the oxygen radical-mediated release of tachykinins. Eur Respir J 1998; 11: 1075-1080.
Dept of Physiology, National Taiwan University, College of Medicine, Taipei, Taiwan

Correspondence: Y-L. Lai

Dept of Physiology

College of Medicine

National Taiwan University

No. 1, Sec. 1, Jen-Ai Road

Taipei

Taiwan

Fax: 886223938235

Keywords: Airway constriction bronchial reactivity

oxygen radicals

tachykinins

Received: July 91997

Accepted after revision January 161998

This investigation was supported by the National Science Council (NSC84-2331-B002-314) and the National Taiwan University College of Medicine (GDFP 84-03).
Decreases in both water vapour and temperature in airways occur during hyperpnoea. Hyperpnoea-induced bronchoconstriction (HIB) is caused by water or heat loss, or both, immediately following hyperpnoea. RAY et al. [1] demonstrated that HIB is mediated by tachykinins in guineapigs. Similarly, SolWAY et al. [2] blocked HIB in guineapigs by using tachykinin receptor antagonists, especially the neurokinin-2 receptor antagonist. However, the relationship between the magnitude of HIB and tachykinin levels is not clear.

It has been demonstrated previously that oxygen radicals play an important role in HIB [3, 4]. In these studies, oxygen radical scavengers and antioxidants significantly reduced tachykinin-mediated HIB. Oxygen radicals may augment HIB via an increase in tachykinin release and/or inactivation of neutral endopeptidase (NEP). NEP is the major degradation enzyme for tachykinins. Oxygen radicals may activate afferent $\mathrm{C}$-fibres of the lungs and induce tachykinin release. This stimulation of afferent $\mathrm{C}$-fibres has been demonstrated in visceral afferents [5]. It is also known that NEP is inactivated by oxygen radicals and is protected by antioxidants [6].

FRANK [7] demonstrated that chronic hypoxia enhances the production of antioxidant enzymes in rat lungs. It is not clear whether the same phenomenon occurs in guineapig lungs. Antioxidants attenuate acute lung oedema induced by xanthine-xanthine oxidase $(\mathrm{X}-\mathrm{XO})$ [8], which is known to generate oxygen radicals [9]. Therefore, the bronchial response to $\mathrm{X}-\mathrm{XO}$ was used to test indirectly the antioxidant defence levels in the lungs before and after chronic hypoxic exposure in guinea-pigs. Following the indirect evidence of increased antioxidant defence levels caused by chronic hypoxia, the question of whether HIB can be attenuated by pretreating guinea-pigs with chronic hypoxia was explored. Furthermore, both tachykinin level and NEP activity were investigated for the possible underlying effects of chronic hypoxia.

\section{Materials and methods}

\section{Preparation of experimental animals}

Thirty young, male Hartley guinea-pigs (from the Animal Centre, National Science Council, Taipei, Taiwan) weighing $232 \pm 14 \mathrm{~g}$ were divided into four groups: control $(n=8)$; chronic hypoxia $(n=7)$; capsaicin pretreatment $(n=$ 7); and capsaicin pretreatment plus chronic hypoxia ( $\mathrm{n}=$ 8). Animals in the control group were placed in an opened hypobaric chamber with no subatmospheric pressure. Animals in the chronic hypoxia group were placed in the closed hypobaric chamber with a barometric pressure of $380 \mathrm{mmHg}$ [10] for 7 days. The animals were only 
exposed to hypoxia from 17:00 to 08:00 h each day (intermittent exposure) and for the rest of the day they were exposed to room air. Using capsaicin pretreatment to deplete tachykinins, a five day chronic capsaicin pretreatment consisting of two consecutive daily doses of 50 $\mathrm{mg} \cdot \mathrm{kg}^{-1}$ and three consecutive daily doses of $100 \mathrm{mg} \cdot \mathrm{kg}^{-1}$ capsaicin administered subcutaneously was begun 9 days before the study [11]. The animals were anaesthetized with a combination of pentobarbital sodium $\left(15 \mathrm{mg} \cdot \mathrm{kg}^{-1}\right)$, fentanyl $\left(0.2 \mathrm{mg} \cdot \mathrm{kg}^{-1}\right)$, and droperidol $\left(10 \mathrm{mg} \cdot \mathrm{kg}^{-1}\right)$ before the subcutaneous injection of capsaicin [11]. For the capsaicin pretreatment plus chronic hypoxia group, the guineapigs began their exposure to hypoxia for 7 days after the initial capsaicin treatment.

On the day of the study, the animals were anaesthetized with sodium pentobarbital (30-40 $\left.\mathrm{mg} \cdot \mathrm{kg}^{-1}\right)$, and the trach-ea, carotid artery and jugular vein were cannulated. After being paralysed with gallamine triethiodide $\left(4 \mathrm{mg} \cdot \mathrm{kg}^{-1}\right)$, the animals were artificially ventilated and tested for bronchial function before and after hyperpnoea with a gas mix-ture of $95 \% \mathrm{O}_{2}-5 \% \mathrm{CO}_{2}$ [3]. The experimental protocol was carried out according to a previous study [3]. The basic sequence for each study had three periods: baseline, hyperpnoea, and recovery. During the baseline period, each animal was ventilated with humidified air (tidal volume, 6 $\mathrm{mL} \cdot \mathrm{kg}^{-1}$; respiratory frequency $(f \mathrm{R}), 60$ breaths $\left.\cdot \mathrm{min}^{-1}\right)$ at room temperature. Then it was hyperventilated for $15 \mathrm{~min}$ with a dry $95 \% \mathrm{O}_{2}-5 \% \mathrm{CO}_{2}$ gas mixture at room temperature (tidal volume, $10 \mathrm{~mL} \cdot \mathrm{kg}^{-1} ; f \mathrm{R}, 150$ breaths $\cdot \mathrm{min}^{-1}$ ). Subsequently, each animal was returned to ventilation with humidified air, the same as that at the baseline period, for $20 \mathrm{~min}$ (i.e. the recovery period).

\section{Evaluation of bronchial function}

During the baseline period, the full maximal expiratory flow-volume (MEFV) manoeuvre was performed two or three times to obtain baseline total lung capacity (TLC; lung volume at airway opening pressure $\left.(P \mathrm{ao})=30 \mathrm{cmH}_{2} \mathrm{O}\right)$. Subsequently, partial MEFV manoeuvres were carried out before and after hyperpnoea to examine the HIB. Since lung inflation to high volume may ameliorate airway constriction $[12,13]$, the partial MEFV manoeuvre was used to avoid the abolition of HIB. The partial MEFV manoeuvre was modified from a previously reported method [14]. Each anaesthetized animal was placed supine inside a whole-body plethysmograph. The flow rate was monitored with a Validyne DP45 differential pressure transducer as the pressure dropped across three layers of 325-mesh wire screen in the wall of the plethysmograph. Lung volume change was obtained via integration of flow. Airway opening pressure was measured with a Statham PM 131 pressure transducer. The lungs were inflated three times to lung volume when $P \mathrm{ao}=10 \mathrm{cmH}_{2} \mathrm{O}$ (instead of the usual $P \mathrm{ao}=30 \mathrm{cmH}_{2} \mathrm{O}$ for the full MEFV manoeuvre). At peak volume during the third inflation, the inflation valve was shut off and immediately another solenoid valve for deflation was automatically turned on. The deflation valve was connected to a $20 \mathrm{~L}$ container with a negative pressure of $40 \mathrm{cmH}_{2} \mathrm{O}$. This negative pressure produced the maximal expiratory flow ( $\left.V^{\prime} \max \right)$. The changes in flow, volume and airway opening pressure were traced on a polygraph (TA11, Gould, Cleveland, USA) and the partial MEFV plot was also stored on a cathode ray storage oscilloscope (VC6025, Hitachi, New York, USA). During artificial ventilation (between the interval of the partial MEFV manoeuvres), tidal volume $(V \mathrm{~T})$ and its accompanying airway opening pressure difference $(\Delta P \mathrm{ao})$ were used to calculate dynamic respiratory compliance $\left(C_{\mathrm{rs}}=V \mathrm{~T} / \Delta P \mathrm{ao}\right)$. The airway opening pressure difference was measured between end-inspiration and end-expiration (i.e., instances of no flow). The $V^{\prime} \max$ at $15 \%$ baseline vital capacity $\left(V^{\prime} \max , 15\right)$, forced expiratory volume in $0.1 \mathrm{~s}(\mathrm{FEV} 0.1)$, and $C \mathrm{rs}$ were used as indicators of bronchoconstriction.

The general experimental procedure consisted of obtaining the values of $V^{\prime} \max , 15, \mathrm{FEV} 0.1$ and $C_{\mathrm{rs}}$ before and after the 15 min hyperpnoea. To explore temporal changes, these values were obtained at 5, 10, 15 and 20 min immediately following the period of hyperpnoea.

Following the functional determination, arterial blood, trachea tissue and lung tissue were sampled. Since arterial blood is the effluent fluid from the lungs, its tachykinin content should be a reliable indicator of tachykinin release from afferent $\mathrm{C}$-fibres in the lungs. Therefore, the level of substance P (a tachykinin) was measured in arterial plasma. Because tachykinins are degraded by NEP in blood, phosphoramidon $\left(10^{-5} \mathrm{M}\right)$, a NEP inhibitor, was added to all blood samples to suppress the degradation of tachykinins following their release. The specimens were centrifuged and the plasma was obtained. The right lung was sampled to determine the level of substance P, whereas the trachea was isolated to measure NEP activity. Plasma and tissues were stored at $-70^{\circ} \mathrm{C}$ for later analyses.

Bronchial responses to capsaicin, substance $P$ and xanthine-xanthine oxidase

To test whether chronic hypoxia induces a change in bronchial responsiveness, airway responses to capsaicin, substance $\mathrm{P}$, and X-XO were compared between chronically hypoxic and control guinea-pigs. For each type of airway responses, animals weighing $213 \pm 30 \mathrm{~g}$ were divided into two groups, control and chronic hypoxia, of six to eight (mean=7.5) animals each. Animals in the control group breathed room air. Before the study, chronically hypoxic animals were exposed to the intermittent hypoxia for 1 week, as mentioned above. On the day of the study, each animal was anaesthetized, cannulated, paralysed, and artificially ventilated.

To test the bronchial responsiveness, capsaicin (10 $\mu \mathrm{g} \cdot \mathrm{kg}^{-1}$ ) was intravenously injected. Then, tidal breathing and the MEFV manoeuvre were carried out both before and 1-20 min after the acute capsaicin challenge. For the substance $\mathrm{P}$ dose-response curve, substance $\mathrm{P}(2,4,8$ or $\left.16 \mu \mathrm{g} \cdot \mathrm{kg}^{-1}\right)$ was injected intravenously. Bronchial function was determined, as described above, before and 1-15 min after each injection. A pause of no less than 30 min was allowed between any two substance $\mathrm{P}$ injections. The lowest dose was administered $\left(2 \mu \mathrm{g} \cdot \mathrm{kg}^{-1}\right)$ first, followed by a higher dose. The highest dose of substance $\mathrm{P}\left(16 \mu \mathrm{g} \cdot \mathrm{kg}^{-1}\right)$ was administered last. To examine the airway response to xanthine-xanthine oxidase, $0.24 \mathrm{~mL}$ xanthine $(0.025 \%$ solution) was instilled intratracheally followed by a similar instillation of $0.24 \mathrm{~mL}$ of xanthine oxidase $(0.122$ $\mathrm{U} \cdot \mathrm{mL}^{-1}$ ) solution. Following each instillation, the lung was 
inflated two or three times with approximately $4 \mathrm{~mL}$ air to force the solution to reach most airways. Bronchial function was determined, as described above, before and 1030 min after $\mathrm{X}-\mathrm{XO}$ administration.

\section{Determination of substance $P$}

Substance $\mathrm{P}$ was extracted from the lung using the method of SARIA et al. [15]. Plasma samples were purified by filtration through a $\mathrm{C}-18$ column. The substance $\mathrm{P}$ level was measured using an enzyme immunoassay [16] by employing a substance $\mathrm{P}$ enzyme immunoassay kit obtained from Cayman Chemical Company (Ann Arbor, MI, USA). The intra-assay coefficients of variation for substance $\mathrm{P}$ were $10 \%$ or less.

\section{Measurement of neutral endopeptidase activity}

Tracheal NEP activity was determined using a modification of the methods of OrLowsKI and WILK [17], HAXHIUPoskuRICA et al. [18], and Kumar (personal communication). The frozen tracheae were thawed and minc-ed into tubes containing $50 \mathrm{mM}$ Tris, $\mathrm{pH}$ 7.4. The tissues were then sonicated for $30 \mathrm{~s}$ at $4^{\circ} \mathrm{C}$ and centrifuged at 17,500 $\mathrm{g}$ for $15 \mathrm{~min}$. The supernatant was removed for analysis.

The reaction mixture $(250 \mu \mathrm{L})$ contained $50 \mu \mathrm{L}$ of tissue extract, $1.25 \mathrm{mM}$ (final concentration) glutaryl-alaninealanine-phenylalanine-4-methoxy-2-naphthylamine substrate, $10 \mu \mathrm{g}$ leucine aminopeptidase and $50 \mathrm{mM}$ Tris buffer, $\mathrm{pH}$ 7.4. The samples were incubated for $1 \mathrm{~h}$ at $37^{\circ} \mathrm{C}$. The reaction was stopped and the coloured product formed by the addition of $2 \mathrm{~mL}$ of $0.0025 \%$ fast garnet GBC in $2 \%$ Brij 35. The optical density was determined spectrophotometrically at $530 \mathrm{~nm}$. The amount of 2-naphthylamine released was calculated from the extinction coefficient of the fast garnet GBC-2-naphthylamine reaction product (molar coefficient $=27,000$ [19]). Each sample was run in duplicate. A $50 \mu \mathrm{L}$ aliquot of each extract was also preincubated for $15 \mathrm{~min}$ at room temperature with $8 \times 10^{-7} \mathrm{M}$ phosphoramidon in $50 \mathrm{mM}$ Tris buffer, $\mathrm{pH}$ 7.4. Substrate and leucine aminopeptidase were then added and the solution was incubated as described above. The protein concentration of the trachea was determined by the method of Lowry et al. [20] with bovine serum albumin as the standard. The phosphoramidon-inhibitable neutral endopeptidase specific activity was expressed as nanomoles of 2-naphthylamine released per milligram of protein per hour.

\section{Statistical analysis}

All values are reported as mean \pm SEM. Analysis of vari-ance (ANOVA) was used to establish the statistical significance of differences among groups. If significant differences among groups were obtained using ANOVA, Duncan's multiple range test was used to differentiate differences between groups. Differences were considered significant for $\mathrm{p}$-values $<0.05$

\section{Results}

Body weight and baseline respiratory parameters are listed in table 1 . The capsaicin pretreatment plus chronic hypoxia group had lower body weight but higher FEV0.1 and $V^{\prime}$ max,15. It is not clear why higher FEV0.1 and $V^{\prime}$ max, 15 were observed in the capsaicin pretreatment plus chronic hypoxia group.

Figure 1 shows hyperpnoea-induced alterations in $V^{\prime} \max , 15$. In the control group, there was a marked decrease in $V^{\prime}$ $\max , 15$ at 5 min following hyperpnoea (fig. 1), which persisted for $15 \mathrm{~min}$ and was abolished by chronic hypoxia, capsaicin pretreatment and capsaicin pretreatment plus chronic hypoxia. Changes in FEV0.1 (fig. 2) and in $C_{\text {rs }}$ (fig. 3) were found to be similar to those in $V^{\prime} \max , 15$ during the recovery phase following $15 \mathrm{~min}$ of hyperpnoea.

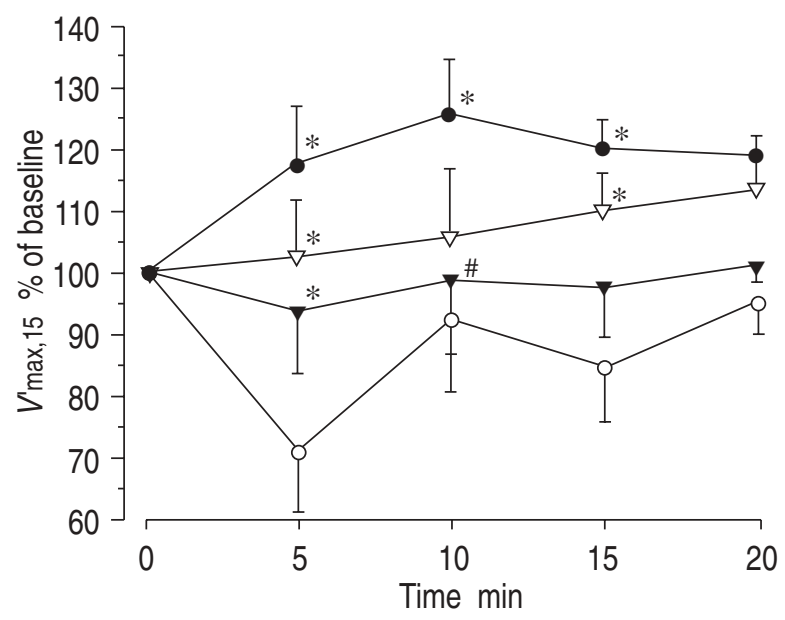

Fig. 1. - Temporal changes in maximal expiratory flow at $15 \%$ vital capacity $\left(V^{\prime} \max , 15\right)$ induced by hyperpnoea in four groups of guineapigs. $\bigcirc$ : control; $\bullet$ : hypoxia; $\nabla$ : capsaicin pretreatment; $\mathbf{\nabla}$ : capsaicin pretreatment + hypoxia. See table 1 for the number of animals in each group. Significant differences $(\mathrm{p}<0.05)$ between groups: *: compared with the control group; \#: compared with the chronic hypoxia group.

Table 1. - Body weight and baseline respiratory values in guinea-pigs

\begin{tabular}{lccccc}
\hline Group & $\mathrm{n}$ & $\begin{array}{c}\text { Body wt } \\
\mathrm{g}\end{array}$ & $\begin{array}{c}C_{\mathrm{rs}} \\
\mathrm{mL} \cdot \mathrm{cmH}_{2} \mathrm{O}^{-1}\end{array}$ & $\begin{array}{c}\mathrm{FEV} 0.1 \\
\mathrm{~mL}\end{array}$ & $\begin{array}{c}V^{\prime} \max , 15 \\
\mathrm{~mL} \cdot \mathrm{s}^{-1}\end{array}$ \\
\hline Control & 8 & $248 \pm 13$ & $0.247 \pm 0.017$ & $4.58 \pm 0.45$ & $38.1 \pm 4.9$ \\
Hypoxia & 7 & $229 \pm 14$ & $0.265 \pm 0.014$ & $4.56 \pm 0.28$ & $42.1 \pm 4.0$ \\
Capsaicin pretreatment & 7 & $253 \pm 19$ & $0.283 \pm 0.021$ & $4.74 \pm 0.40$ & $44.4 \pm 7.3$ \\
Capsaicin pretreatment + hypoxia & 8 & $200 \pm 11^{*}$ & $0.277 \pm 0.008$ & $5.78 \pm 0.29 *$ & $62.6 \pm 7.3^{*}$ \\
\hline
\end{tabular}

Values are mean \pm SEM. $\mathrm{n}$ : number of animals; wt: weight; $C_{\text {rs: }}$ respiratory compliance; FEV0.1: forced expiratory volume in $0.1 \mathrm{~s} ; V^{\prime} \max , 15$ : maximal expiratory flow rate at $15 \%$ of baseline vital capacity. $*$ : $<<0.05$, compared with the control group. 


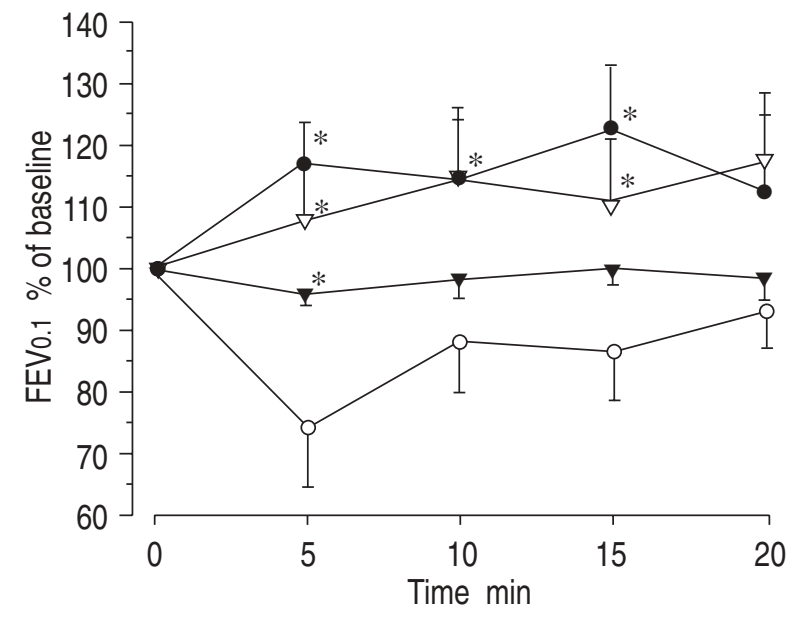

Fig. 2. - Temporal changes in forced expiratory volume in $0.1 \mathrm{~s}$ (FEV 0.1$)$ induced by hyperpnoea in four groups of guinea-pigs. $\bigcirc$ : control; $\bullet$ : hypoxia; $\nabla$ : capsaicin pretreatment; $\mathbf{\nabla}$ : capsaicin pretreatment + hypoxia. See table 1 for the number of animals in each group. Significant differences $(\mathrm{p}<0.05)$ between groups: *: compared with the control group.

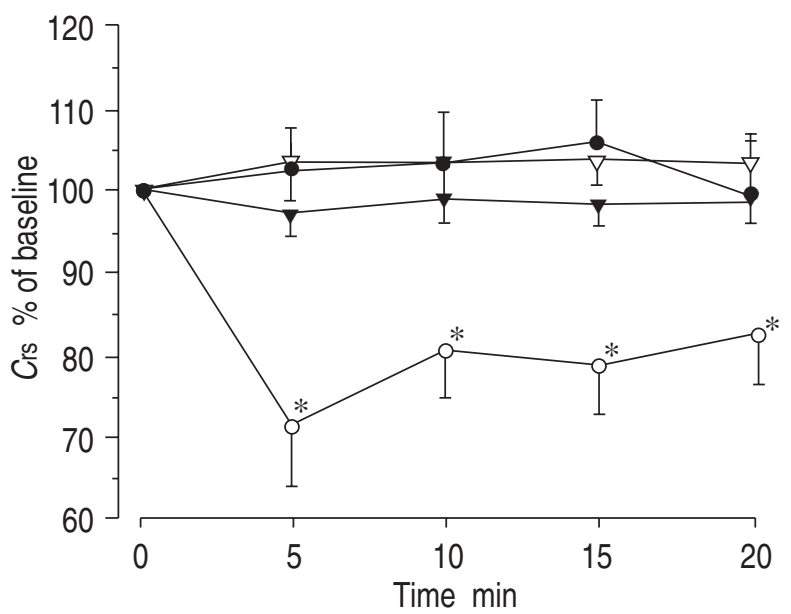

Fig. 3. - Temporal changes in dynamic respiratory compliance $\left(C_{\mathrm{rs}}\right)$ induced by hyperpnoea in four groups of guinea-pigs. $\bigcirc$ : control; $\bullet$ : hypoxia; $\nabla$ : capsaicin pretreatment; $\boldsymbol{\nabla}$ : capsaicin pretreatment + hypoxia. See table 1 for the number of animals in each group. Significant differences $(\mathrm{p}<0.05)$ between groups: *: compared with the control group.

Plasma and lung tissue substance $\mathrm{P}$ values as well as tracheal NEP activity measured in samples obtained at the end of the functional study are shown in table 2. The plasma substance $P$ level was significantly higher in the control group than in all other groups. Capsaicin plus chronic hypoxia caused a significant decrease in the lung tissue substance P level. No significant differences in tracheal NEP activity could be demonstrated between groups.

No significant differences in bronchial response $(C \mathrm{rs})$ to either capsaicin (fig. 4) or substance P (fig. 5) were found between the control and the chronic hypoxia groups. The bronchial response $(C$ rs $)$ to $\mathrm{X}-\mathrm{XO}$ was, however, attenuated in the chronic hypoxia group (fig. 6).

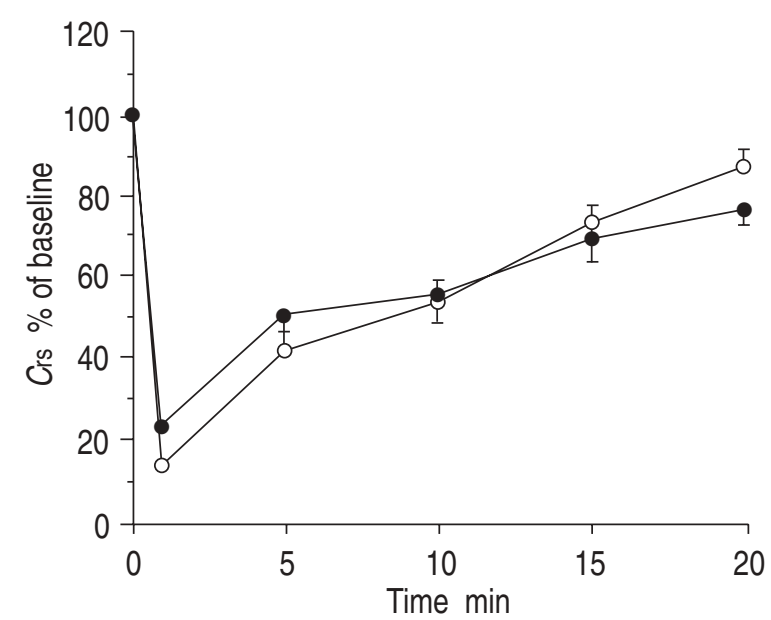

Fig. 4. - Capsaicin-induced alteration in dynamic respiratory compliance $(C \mathrm{rs})$ in the control $(\bullet ; n=6)$ and hypoxia $(O ; n=7)$ groups of animals. No significant differences in bronchial response to capsaicin were found between the control and chronic hypoxia groups.

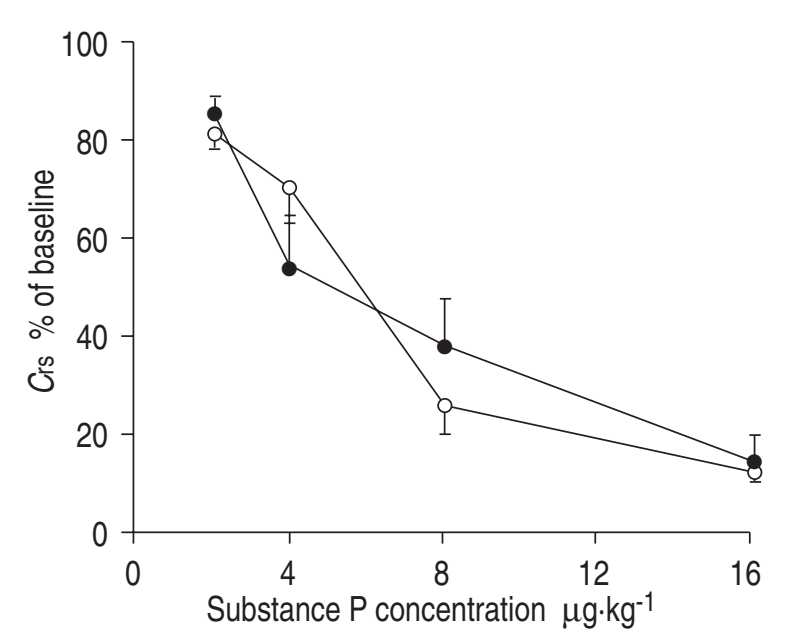

Fig. 5. - Substance P-induced alteration in dynamic respiratory compliance $(C$ rs $)$ in the control $(\bullet ; n=7)$ and hypoxia $(O ; n=8)$ groups of animals. No significant differences in bronchial response to substance $\mathrm{P}$ were found between the control and chronic hypoxia groups.

Table 2. - Substance P (SP) levels and tracheal neutral endopeptidase (NEP) activity in guinea-pigs

\begin{tabular}{lcccc}
\hline & $\begin{array}{c}\text { Control } \\
\mathrm{n}=6\end{array}$ & $\begin{array}{c}\text { Hypoxia } \\
\mathrm{n}=6\end{array}$ & $\begin{array}{c}\text { Capsaicin pretreatment } \\
\mathrm{n}=7\end{array}$ & $\begin{array}{c}\text { Capsaicin pretreatment }+ \\
\text { hypoxia } \mathrm{n}=8\end{array}$ \\
\hline $\begin{array}{l}\text { SP levels } \\
\text { Plasma fmol } \cdot \mathrm{mL}^{-1}\end{array}$ & $90.1 \pm 8.4$ & $42.1 \pm 13.0^{*}$ & $47.3 \pm 4.8^{*}$ & $41.5 \pm 7.6^{*}$ \\
$\quad \begin{array}{l}\text { Lung tissue pmol.g } \\
\text { NEP activity }\end{array}$ & $6.94 \pm 1.32$ & $6.04 \pm 0.56$ & $4.69 \pm 0.78$ & $3.11 \pm 0.20^{*}$ \\
$\mathrm{nmol} \cdot \mathrm{mg} \mathrm{protein}{ }^{-1} \cdot \mathrm{h}^{-1}$ & $315 \pm 27$ & $370 \pm 27$ & $361 \pm 22$ & $324 \pm 28$ \\
\hline
\end{tabular}

Values are mean \pm SEM. $n$ : number of animals. $*: p<0.05$, compared with the control group. 


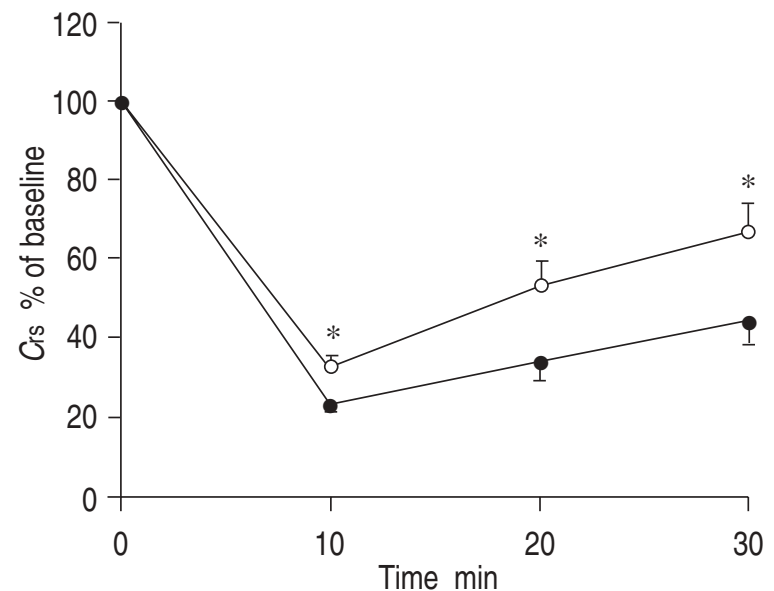

Fig. 6. - Alteration in dynamic respiratory compliance $(C \mathrm{rs})$ induced by xanthine and xanthine oxidase in the control $(\bullet ; n=8)$ and hypoxia $(O ; n=8)$ groups of animals. *: significant difference in bronchial response to xanthine-xanthine oxidase between the control and chronic hypoxia groups $(\mathrm{p}<0.05)$.

\section{Discussion}

Chronic hypoxia, antioxidants and hyperpnoea-induced bronchoconstriction

Hyperventilation with a dry $95 \% \mathrm{O}_{2}-5 \% \mathrm{CO}_{2}$ gas mixture induced marked decreases in $V^{\prime}$ max, 15 , FEV0.1, and $C$ rs. These decreases were significantly attenuated by chronic hypoxia. It has been demonstrated that $V^{\prime}$ max is closely associated with the bronchial diameter [21], and dynamic compliance is often used as an indicator of change in dimension of the peripheral airways [22]. Therefore, it was demonstrated that pre-exposure of guinea-pigs to hypobaric hypoxia for 1 week attenuates HIB. It is known that HIB in guinea-pigs is mediated via tachykinins [1, 2]. Could this attenuation be related to a dilatory effect of chronic hypoxia which suppresses airway constriction in response to tachykinins? PerReault et al. [23] demonstrated in anaesthetized rabbits that chronic hypoxia does not significantly alter the baseline respiratory resistance value or the histamine-induced increase in respiratory res-istance, implying that chronic hypoxia does not have a general bronchodilatory effect. Although the same effect was not investigated in guinea-pigs, the dilatory action of chronic hypoxia is perhaps unlikely.

FRANK [7] showed that chronic hypoxia enhances the production of antioxidant enzymes in rat lungs. However, it is not known whether the same enhancement occurs in guinea-pig lungs. KATSUMATA et al. [24] demonstrated that the administration of $\mathrm{X}-\mathrm{XO}$ produces oxygen radicals. The same administration of $\mathrm{X}-\mathrm{XO}$ produced a significantly $(p<0.05)$ smaller degree of airway constriction in the chronic hypoxia group than in the control group (fig. 6). Therefore, the results imply that the ability to generate oxygen radicals is decreased in the chronically hypoxic guinea pig lungs. This decrease in oxygen radical production might be closely related to the increased antioxidants in the guinea-pig lungs following chronic hypoxia. This speculation is based on the fact that antioxidants attenuate lung oedema caused by X-XO [8], which generates oxygen radicals [9]. This increase in antioxidants, then, may be related closely to the attenuation of HIB. During the course of prolonged hypoxia, the first period of acute hypoxia should augment the production of oxygen radicals $[25,26]$. Subsequently, increased oxygen radicals may cause an increase in the synthesis of antioxidants [7] during the latter period of prolonged hypoxia.

Several lines of evidence from previous studies support the idea that HIB is suppressed by antioxidants and augmented by oxygen radicals. 1) Marked HIB occurs following $15 \mathrm{~min}$ of hyperpnoea with a mixture of $95 \% \mathrm{O}_{2}-5 \%$ $\mathrm{CO}_{2}$ gas mixture but not with $5 \% \mathrm{CO}_{2}$ in air [3]. Since high $\mathrm{O}_{2}$ can generate oxygen free radicals [27], the effect of $95 \% \mathrm{O}_{2}-5 \% \mathrm{CO}_{2}$ may be closely related to oxygen radicals. 2) Scavengers of hydroxyl radicals (dimethylthiourea) [28] as well as the combination of superoxide dismutase and catalase, significantly suppressed the HIB induced by hyperpnoea with a high $\mathrm{O}_{2}$ gas mixture [3]. 3) HIB was found to occur more frequently in sensitized rabbits [29]. It is known that there is an increase in oxygen radical production in sensitized animals [30]. However, HIB in asthmatics probably reflects changes in the temperature and/ or osmolarity of airways. Further studies are needed to test whether HIB in asthmatics relates to antioxidants or oxygen radicals.

\section{Tachykinins and hyperpnoea-induced bronchoconstriction}

Innervation of the airways and lungs with afferent $\mathrm{C}$ fibres has been demonstrated in several species of mammals, including humans and guinea pigs [31]. Activation of afferent C-fibres causes the release of tachykinins which, in turn, induces bronchoconstriction, vascular leakage and the secretion of mucus [32, 33]. Afferent $\mathrm{C}$-fibres can be stimulated by hyperpnoea $[1,3]$ and by other irritants [33, 34]. Tachykinins (mainly substance $P$ and neurokinin $A$ in mammals [15]) and a calcitonin gene-related peptide are simultaneously released following the activation of afferent C-fibres [32]. Tachykinins are the major mediators that induce airway constriction following afferent $\mathrm{C}$-fibre sti-mulation [32], and are therefore the mediators of the ex-citatory nonadrenergic-noncholinergic system. Pretreatment with capsaicin should decrease the tachykinin content in lung tissue. A significant decrease was demonstrated in the capsaicin pretreatment plus hypoxia group but not in the capsaicin alone group (table 2). Although there was a trend towards a decrease, the failure of capsaicin pretreatment alone to reduce significantly the content of substance $P$ in lung tissue could be due to large variations in these values.

Chronic hypoxia did not alter substance P-induced airway constriction (fig. 4). Since substance P acts directly on airway smooth muscle, the result may imply that chronic hypoxia does not affect the reactivity of bronchial smooth muscle. As mentioned above, the mediators for HIB are tachykinins in guinea-pigs $[1,2]$. There are no data in the literature, as far as the authors are aware, to illustrate the relationship between HIB and tachykinin content in lung tissue and plasma. If there is no change in the characteristics of tachykinin receptors during the course of HIB, the magnitude of HIB should be related closely to released tachykinins. Chronic hypoxia attenuated HIB (figs. 1-3) and thus should decrease tachykinin release according to the above reasoning. Chronic hypoxia was found to cause a significant decrease in the substance $\mathrm{P}$ level in arterial plasma, implying that the findings support this reasoning. It is tempting to speculate that there is a temporal change 
in the release of tachykinins during the course of prolonged hypoxia. During the acute phase, increased oxygen radicals can activate afferent $\mathrm{C}$-fibres [5] and enhance tachykinin release. In addition, oxygen radicals can inactivate NEP. Since NEP is the main degradation enzyme for tachykinins, its inactivation should augment the activity of tachykinins. Antioxidants increase following prolonged hypoxia [7], and this increase should then suppress the activation of afferent $\mathrm{C}$-fibres and protect NEP. Consequently, these alterations during prolonged hypoxia could attenuate HIB.

No significant difference in neutral endopeptidase activity, however, was observed between the control and the hypoxia groups (table 2). Therefore, it seems unlikely that the suppression of hyperpnoea-induced bronchoconstriction by chronic hypoxia occurs via an alteration in neutral endopeptidase activity.

Acknowledgements: The authors thank S.H. Kuo and G.-Y. Liu for technical assistance.

\section{References}

1. Ray DW, Hernandez C, Leff AR, Drazen JM, Solway J. Tachykinins mediate bronchoconstriction elicited by isocapnic hyperpnea in guinea pigs. J Appl Physiol 1989; 66: 1108-1112.

2. Solway J, Kao BM, Jordan IE, et al. Tachykinin receptor antagonists inhibit hyperpnea-induced bronchoconstriction in guinea pigs. J Clin Invest 1993; 92: 315-323.

3. Fang ZX, Lai Y-L. Oxygen radicals in bronchoconstriction of guinea pigs elicited by isocapnic hyperpnea. $J$ Appl Physiol 1993; 74: 627-633.

4. Lai Y-L, Fang ZX, Zhang H-Q. Noncholinergic airway constriction. Role of axon reflex and oxygen radicals. Chin J Physiol 1993; 36: 133-140.

5. Longhurst JC, Dittman LE. Hypoxia, bradykinin, and prostaglandins stimulate ischemically sensitive visceral afferents. Am J Physiol 1987; 253: H556-H567.

6. Borson DB. Roles of neutral endopeptidase in airways. Am J Physiol 1991; 260: L212-L225.

7. Frank L. Protection from $\mathrm{O}_{2}$ toxicity by preexposure to hypoxia: lung antioxidant enzyme role. J Appl Physiol 1982; 53: 475-482.

8. Tate RM, VanBenthuysen KM, Shaby DM, McMurtry IF, Repine IE. Oxygen-radical-mediated permeability edema and vasoconstriction in isolated perfused rabbit lungs. $\mathrm{Am}$ Rev Respir Dis 1982; 126: 802-806.

9. Kellogg EW III, Fridovich I. Superoxide, hydrogen peroxide, and singlet oxygen in lipid peroxidation by a xanthine oxidase system. J Biol Chem 1975; 250: 8812-8817.

10. Chen C-F, Chien C-T, Fang H-Z, Chiu IS. Effects of atrial natriuretic factor in chronic hypoxic spontaneously hypertensive rats. Hypertension 1991; 18: 355-359.

11. Lai Y-L, Cornett AF. Substance P-inducing massive postmortem bronchoconstriction in guinea pig lungs. J Appl Physiol 1987; 62: 746-751.

12. Loring SH, Ingram RH Jr, Drazen IM. Effects of lung inflation on airway and tissue responses to aerosol histamine. J Appl Physiol 1981; 51: 806-811.

13. Ray DW. Garland A, Hernandez C, Eappen S, Alger L, Solway J. Time course of bronchoconstriction induced by dry gas hyperpnea in guinea pigs. J Appl Physiol 1991; 70: 504-510.

14. Lai Y-L. Maximal expiratory flow in the guinea-pig. Lung 1988; 166: 303-313.

15. Saria A, Martling C-R, Yan Z, Theodorsson-Norheim E, Gamse R, Lundberg JM. Release of multiple tachykinins from capsaicin-sensitive sensory nerves in the lung by bradykinin, histamine, dimethylphenyl piperazinium, and vagal nerve stimulation. Am Rev Respir Dis 1988; 137: 1330-1335.

16. Tai H-H. Enzyme immunoassay. In: Swarbrick J, Boylan JC, eds. Encyclopedia of Pharmaceutical Technology. Vol. 5, New York, Dekker, 1992; pp. 201-233.

17. Orlowski M, Wilk S. Purification and specificity of a membrane-bound metalloendopeptidase from bovine pituitary. Biochemistry 1981; 20: 4942-4950.

18. Haxhiu-Poskurica B, Haxhiu MA, Kumar GK, Miller MJ, Martin RJ. Tracheal smooth muscle responses to substance $\mathrm{P}$ and neurokinin A in the piglet. J Appl Physiol 1992; 72: 1090-1095.

19. Barrett AJ. Cathepsin B and other thiol proteases. In: Barrett AJ, ed. Proteinases in Mammalian Cells and Tissues. (Research Monographs in Cell and Tissue Physiology. Vol. 2. General Editor, Dingle JT) Amsterdam: North-Holland, 1977; pp. 181-208.

20. Lowry OH, Rosebrough NJ, Farr AL, Randall RJ. Protein measurement with the folin phenol reagent. J Biol Chem 1951; 193: 265-275.

21. Olive JT Jr, Hyatt RE. Maximal expiratory flow and total respiratory resistance during induced bronchoconstriction in asthmatic subjects. Am Rev Respir Dis 1972; 106: 366-376.

22. Drazen JM. Physiologic basis and interpretation of common indices of respiratory mechanical function. Environ Health Perspect 1976; 16: 11-16.

23. Perreault S, Saunier C, Duvivier C, Peslin R, Ong H, du Souich P. Influence of chronic hypoxia on salbutamol tissular concentrations and on respiratory resistance in anesthetized rabbits. Am J Respir Crit Care Med 1994; 150: 1374-1378.

24. Katsumata U, Miura M, Ichinose M, et al. Oxygen radicals produce airway constriction and hyperresponsiveness in anesthetized cats. Am Rev Respir Dis 1990; 141: 11581161.

25. Stahl GL, Pan H-L, Longhurst JC. Activation of ischemia- and reperfusion-sensitive abdominal visceral Cfiber afferents. Role of hydrogen peroxide and hydroxyl radicals. Circ Res 1993; 72: 1266-1275.

26. Zini I, Tomasi A, Grimaldi R, Vannini V, Agnati LF. Detection of free radicals during brain ischemia and reperfusion by spin trapping and microdialysis. Neurosci Lett 1992; 138: 279-282.

27. Freeman BA, Topolosky MK, Crapo JD. Hyperoxia increases oxygen radical production in rat lung homogenates. Arch Biochem Biophys 1982; 216: 477-484.

28. Fox RB. Prevention of granulocyte-mediated oxidant lung injury in rats by a hydroxyl radical scavenger, dimethylthiourea. J Clin Invest 1984; 74: 1456-1464.

29. Koyama S, Ohtsuka A, Horie T. Eucapnic hyperventilation-induced bronchoconstriction in rabbits. Tohoku $J$ Exp Med 1992; 168: 611-619.

30. Ikuta N, Sugiyama S, Takagi K, Satake T, Ozawa T. Implication of oxygen radicals on airway hyperresponsiveness after ovalbumin challenge in guinea pigs. Am Rev Respir Dis 1992; 145: 561-565.

31. Wharton J, Polak JM, Bloom SR, Will JA, Brown MR, Pearse AGE. Substance P-like immunoreactive nerves in mammalian lung. Invest Cell Pathol 1979; 2: 3-10.

32. Barnes PJ, Baraniuk JN, Belvisi MG. Neuropeptides in the Respiratory tract. Part 1. Am Rev Respir Dis 1991; 144: 1187-1198.

33. Lundberg JM, Saria A. Capsaicin-induced desensitization of airway mucosa to cigarette smoke, mechanical and chemical irritants. Nature 1983; 302: 251-253.

34. Martins MA, Shore SA, Drazen JM. Capsaicin-induced release of tachykinins: effects of enzyme inhibitors. $J$ Appl Physiol 1991; 70: 1950-1956. 